\title{
Effect of IGF-I and PDGF administered in vivo on the expression of osteoblast-related genes in old rats
}

\author{
H Tanaka ${ }^{1,2}$, A Wakisaka ${ }^{1,2}$, H Ogasa ${ }^{1,2}$, S Kawai ${ }^{1}$ \\ and C T Liang ${ }^{2,3}$ \\ ${ }^{1}$ Department of Orthopedic Surgery, Yamaguchi University School of Medicine, 1-1-1 Minamikogushi, Ube, Yamaguchi 755-8505, Japan \\ ${ }^{2}$ Gerontology Research Center, National Institute on Aging, National Institutes of Health, 4940 Eastern Avenue, Baltimore, Maryland 21224, USA \\ ${ }^{3}$ National Health Research Institutes, Taipei, 115 Taiwan \\ (Requests for offprints should be addressed to H Tanaka, Department of Orthopedic Surgery, Yamaguchi University School of Medicine, \\ 1-1-1 Minamikogushi, Ube, Yamaguchi 755-8505, Japan; Email: htanaka@po.cc.yamaguchi-u.ac.jp)
}

\begin{abstract}
In order to establish the cellular basis for using growth factors as possible therapeutic agents for the age-dependent deficit in bone formation activity, we examined the individual and combined effects of IGF-I and/or plateletderived growth factor (PDGF) on the gene expression of osteoblast-related markers in male rats.

The expression of osteoblast markers was examined in the femurs of adult and old rats following marrow ablation, which amplifies gene expression activity. The mRNA levels of collagen ${ }_{\alpha 1}$ (I) (COLI), alkaline phosphatase (AP), osteopontin (OP) and osteocalcin (OC) were significantly lower in the old as compared with the adult rats. To determine whether growth factors can abolish the agerelated deficits in mRNA expression in old bone, PDGF and/or IGF-I were infused directly into the right femur for 5 days following marrow ablation. The contralateral femur was infused with vehicle only and used as a control. PDGF stimulated the expression of OP mRNA in both adult and old rats, whereas COLI, AP and OC mRNAs were not affected. IGF-I infusion did not have a significant effect on mRNA expression in adult rats. In contrast, treatment with IGF-I significantly enhanced the
\end{abstract}

mRNA levels of COLI, AP and OP in old rats. To examine whether the combination of both factors could affect the expression of osteoblast markers synergistically, PDGF and IGF-I were infused together. In adult bones, the combined treatment with PDGF and IGF-I caused a slight increase in the level of $\mathrm{OP}$ gene expression but no change in AP, OC or COLI genes. Although neither IGF-I nor PDGF alone was effective in stimulating the expression of $\mathrm{OC}$, the combined treatment in old bones enhanced OC expression significantly. The expression of COLI, AP and OP was also stimulated, but the stimulation was no different from that of IGF-I alone. In PDGF plus IGF-I treatment with a high dose, no dose-response effects were observed.

Within the limits of the present study, it is suggested that IGF-I and, to a much lesser extent, PDGF may partially restore the deficit in the expression of osteoblast markers in old bones, and that the combination of both factors is slightly better than IGF-I alone in stimulating OC expression.

Journal of Endocrinology (2002) 174, 63-70

\section{Introduction}

The loss of bone mass in senescence can be attributed to an impairment of bone formation which is regulated by bone-seeking hormones or growth factors, but the underlying cause of reduced bone formation activity in aging is still unclear (Christiansen 1992). It is widely accepted that estrogen has an important protective effect on bone and that the loss of this protection after menopause contributes to the pathogenesis of postmenopausal osteoporosis. Although this protective effect of estrogen is thought to be largely mediated by the inhibition of bone resorption, recent evidence suggests that stimulation of osteoblast activity may also be involved (Samuels et al. 1999, 2000).
Bone growth factors are a class of mediators that regulate the proliferation and differentiation of osteoblasts during the bone formation process. Many studies that examine the effects of growth factors on bone formation suggest that growth factors can be used potentially as therapeutic agents in the treatment of bone loss associated with aging.

Platelet-derived growth factor (PDGF) is one of the biological mediators of bone formation (Howes et al. 1988, Centrella et al. 1989, Pfeilschifter et al. 1990). Earlier studies have shown that PDGF enhances DNA and collagen synthesis in rat osteoblast cultures (Centrella et al. 1989) and increases bone matrix deposition in cultured calvaria (Pfeilschifter et al. 1990). In an in vivo study, PDGF was also found to enhance bone formation in 
subcutaneously implanted matrix (Howes et al. 1988). Insulin-like growth factor-I (IGF-I) has also been proposed to be a major stimulator of bone formation (Isgaard et al. 1986, Schlechter et al. 1986, Spencer et al. 1991). IGF-I functions as both an autocrine and paracrine regulator to promote the growth and differentiation of bone cells (Canalis 1980, Hock et al. 1988). It is generally believed that PDGF is a competence factor and IGF-I is a progression factor. Both factors act via different receptors and regulate different processes of bone formation. The question arises, then, of whether the two factors may interact and collaborate to enhance the lineage of osteoblast cells and stimulate bone formation. There are several reports of a combined effect of PDGF and IGF-I. Canalis et al. (1989) demonstrated that the combination of the two factors had an additive effect on DNA synthesis in rat calvaria cells. A combined effect on the stimulation of bone matrix apposition in vitro was also reported (Pfeilschifter et al. 1990). Using stromal cell cultures, we were able to show that IGF-I and PDGF can stimulate cell proliferation in an additive manner (Tanaka \& Liang 1995). In an in vivo study, the synergistic action of PDGF and IGF-I was demonstrated in wound healing (Lynch et al. 1987), periodontal bone formation (Lynch et al. 1991) and bone repair in a cortical defect model (Lynch et al. 1994). However, in order to assess the individual, additive, or synergistic effects of growth factors on bone formation at the cellular and molecular levels, histologic analysis as used in most previous studies is insufficient, since the effect is expressed as the net result of a number of cellular events.

In the past, we have documented the use of a marrow ablation model to investigate the age-related impairment in osteogenic capacity (Liang et al. 1992). This procedure induces rapid proliferation of osteoblasts and medullary bone formation and allows us to assess the process of osteogenic differentiation in vivo at both the cellular and molecular levels. Our previous results using this model showed that the mRNA levels of osteoblast markers were decreased in old rats and were partially restored by an IGF-I infusion (Liang et al. 1992, Tanaka et al. 1994).

The present study was undertaken to explore the possibility that growth factor can be used to restore the age-related impairment in bone formation activity. We infused PDGF and IGF-I individually and in combination into the marrow cavity after marrow ablation to determine whether the combination of PDGF and IGF-I is superior to the use of either factor alone in stimulating the expression of osteoblast markers.

\section{Materials and Methods}

\section{Animals}

Adult (6-month-old) and old (24-month-old) male Wister rats were supplied by the Animal Facility, Gerontology
Research Center, National Institute on Aging. We used male rats to avoid the possible influence of decreased estrogen secretion in female rats, which may complicate the interpretation of the results. Throughout the experiment, the animals were housed with a cycle of $12 \mathrm{~h}$ of light and $12 \mathrm{~h}$ of darkness, and fed ad libitum standard National Institute of Health rat chow consisting of $23.5 \%$ protein, $1 \cdot 2 \%$ calcium and $1 \cdot 0 \%$ phosphate.

\section{Bone marrow aspiration}

Femoral bone marrow was aspirated as described previously (Patt \& Maloney 1975). Briefly, the rats were anesthetized with ketamine $(50 \mathrm{mg} / \mathrm{kg})$ and xylazine $(10 \mathrm{mg} / \mathrm{kg})$. A longitudinal incision was made across the medial aspect of the knee to expose the bone. A $1.6 \mathrm{~mm}$ hole was drilled through the femoral intercondylar space into the marrow cavity. The marrow was removed through a cannula inserted through the hole and attached to a vacuum line, then the marrow cavity was irrigated with saline. For the growth factor experiment, an Alzet minipump containing growth factor solution was inserted subcutaneously on the back of the rat adjacent to the hip joint. A polyethylene catheter was used to deliver growth factor into the right femoral cavity. The left femur was used as a control. The skin wound was closed with wound clips. Human recombinant PDGF-B homodimer (Bachem, Inc., Torrance, CA, USA) and IGF-I (Bachem, Inc.) were infused for 5 days. The rats were killed at day 6 after the surgical procedure. Both femora were removed and stored at $-80{ }^{\circ} \mathrm{C}$ until they were processed. The minipumps were recovered and the residual solution in the pump was estimated to ensure that the infusion had proceeded as expected. This protocol was approved by the Animal Care and Use Committee at the Gerontology Research Center, National Institute on Aging.

\section{$R N A$ preparation}

Bones were pulverized with a mortar and pestle prechilled in dry ice. RNA was extracted from the bones as described previously (Nemeth et al. 1989). Briefly, the powdered bone was homogenized in a $6 \mathrm{M}$ guanidine thiocyanate (Fluka Biochemika, Buchs, Switzerland) solution containing 1.5\% N-laurosarcosine (Sigma Co., St Louis, MO, USA), $67 \cdot 5 \mathrm{mM}$ potassium acetate and $0 \cdot 1 \%$ antiform A (Sigma Co.). The debris was removed by centrifugation at $8000 \mathrm{~g}$ for $40 \mathrm{~min}$, and the supernatants were loaded onto a $5 \cdot 6 \mathrm{M}$ cesium chloride cushion. Total RNA was separated by density gradient ultracentrifugation at $145000 \mathrm{~g}$ for $18 \mathrm{~h}$. The RNA pellet was dissolved in DEPC-treated $\mathrm{H}_{2} \mathrm{O}$, extracted with chloroform/isobutanol, and precipitated with 70\% ethanol at $-20{ }^{\circ} \mathrm{C}$. The purity of the RNA was monitored by the ratio of the absorbances of the samples at $260 \mathrm{~nm}$ and $280 \mathrm{~nm}$. 


\section{Northern analysis}

Total RNA $(15 \mu \mathrm{g})$ was denatured, separated on a $1 \%$ agarose gel (FMC Co., Rockland, ME, USA) and transferred to Gene Screen paper (New England Nuclear, Boston, MA, USA). Inserts of cDNA were released from the plasmid by restriction enzyme digestion and separated on a $0 \cdot 75 \%$ agarose gel. The appropriate cDNA fragment was extracted from slices of the agarose gel with a Prep-AGene kit (Bio-Rad, Richmond, CA, USA). The cDNA probes used were rat alkaline phosphatase (AP) $(0.6 \mathrm{~kb}$, EcoRI) (Noda et al. 1987), rat collagen $\alpha_{1}$ (I) (COLI) (1.3 kb, PstI) (Genovese et al. 1984), rat osteocalcin (OC) $(0.5 \mathrm{~kb}$, EcoRI) (Weinreb et al. 1990) and rat osteopontin (OP) $\left(1.3 \mathrm{~kb}\right.$, EcoRI) (Yoon et al. 1987). ${ }^{32} \mathrm{P}-L a b e l e d$ probes were prepared with a multiprime labeling kit (Amersham Co., Arlington Heights, IL, USA). The blots were hybridized at $42{ }^{\circ} \mathrm{C}$ for $24 \mathrm{~h}$ in $50 \%$ formamide. After hybridization, the blots were washed with $2 \times$ SSC $(0 \cdot 15 \mathrm{M} \mathrm{NaCl}$ and $0.015 \mathrm{M}$ sodium citrate) and $0 \cdot 1 \% \mathrm{SDS}$ twice at room temperature, $1 \times \mathrm{SSC}$ and $0 \cdot 1 \%$ SDS at $50{ }^{\circ} \mathrm{C}$, and $0.5 \times \mathrm{SSC}$ and $0.1 \%$ SDS at $60{ }^{\circ} \mathrm{C}$. Autoradiograms were exposed at $-70{ }^{\circ} \mathrm{C}$ with an intensifier screen.

\section{Dot blot analysis}

Aliquots of $0 \cdot 5-5 \cdot 0 \mu \mathrm{g}$ total RNA were applied onto the Gene Screen membrane with a Minifold apparatus (Schleicher \& Schuell, Waburn, MA, USA). The membrane was baked at $80{ }^{\circ} \mathrm{C}$ for $2 \mathrm{~h}$ to immobilize the RNA and then hybridized with various cDNA probes, as described above. A polythymidylate probe was used to determine poly(A) ${ }^{+}$RNA (Hollander \& Fornace 1990). Briefly, the ${ }^{32} \mathrm{P}-$ labeled probes were prepared by using oligo $(\mathrm{dT})^{12-18}$ as primer and poly $\mathrm{A}$ as template to synthesize ${ }^{32} \mathrm{P}$-poly $(\mathrm{dT})$. Hybridization and washing of the dot blots followed the procedures described. The radioactivity of each dot on the filter was measured with a Betascope 603 Blot analyzer (Betagen Corp., Waltham, MA, USA). The level of each mRNA was normalized with poly $(\mathrm{A})^{+} \mathrm{RNA}$ to correct for variations in the amount of RNA applied. To test whether the changes were specific, the content of poly $(A)^{+}$RNA was also determined. No significant difference in poly $(\mathrm{A})^{+} \mathrm{RNA}$ was observed between adult and old bone or between control and treated bone relative to total RNA.

\section{Statistical analysis}

All data are expressed as means \pm S.E. Statistical analyses were performed with a Student's $t$-test.

\section{Results}

Effect of age on the gene expression of osteoblast markers following marrow ablation

We have previously examined the mRNA expression patterns of osteoblast markers in the bone marrow ablation model and showed that maximal activation was observed at day 6 (Liang et al. 1992). To assess the effect of age on gene expression activity, we examined the mRNA levels of COLI, AP, OP and OC in the femurs at day 6 after marrow ablation. For quantitation of the mRNA levels, we analyzed the relative mRNA content by dot blot analysis. In the uninjured femurs, the mRNA levels of osteoblast markers were very low (data not shown), but the activity was enhanced significantly by marrow ablation. The mRNA levels in the injured femurs were significantly lower in the old than in the adult rats $(23 \%, 56 \%, 46 \%$ and $23 \%$ respectively) (Fig. 1). The effect of age on gene expression was also analyzed by Northern blot hybridization. Figure 2 shows a representative result using randomly selected bone samples from each age group.

\section{Effect of PDGF on the gene expression of osteoblast markers}

In order to study whether growth factor can abolish the age-related deficits in mRNA expression in old bone, PDGF was infused locally into the right femur after marrow ablation and the effect on gene expression was examined. The left femur was infused with vehicle only and served as the control, while the contralateral bone was infused with 25 or $50 \mathrm{ng} /$ day growth factor for 5 days. The results are expressed as the ratio of the mRNA level of the treated leg to that of the control leg. In old rats, the expression of OP mRNA was significantly stimulated by 25 and $50 \mathrm{ng}$ /day PDGF (33\% and 30\%), whereas the expression of COLI, AP and OC was not affected by PDGF treatment. A similar PDGF effect was observed in adult rats (Fig. 3).

\section{Effect of IGF-I on the gene expression of osteoblast markers}

In adult rats, IGF-I did not have a significant effect on gene expression. In contrast, IGF-I was moderately effective in stimulating gene expression in old bones (Fig. 3). Treatment with IGF-I at $25 \mathrm{ng} /$ day significantly enhanced the mRNA levels of COLI, AP and OP (41\%, $20 \%$ and $38 \%$ respectively). OC mRNA was not affected by IGF-I treatment. At $50 \mathrm{ng} /$ day IGF-I, the effect was similar to that obtained with $25 \mathrm{ng}$ /day IGF-I.

\section{Effect of PDGF plus IGF-I on the gene expression of osteoblast markers}

In adult bones, combined treatment of PDGF with IGF-I caused an increase in the level of OP gene expression by about $20 \%$ and no change in AP, OC and COLI genes. When PDGF and IGF-I were infused into old bones at $25 \mathrm{ng} /$ day, the expression of OC mRNA was significantly enhanced (38\%) (Fig. 3). The two agents also had a significant effect on the mRNA expression of COLI, AP and OP $(39 \%, 29 \%$ and $36 \%$ respectively), although these levels of mRNA were not significantly higher than those 


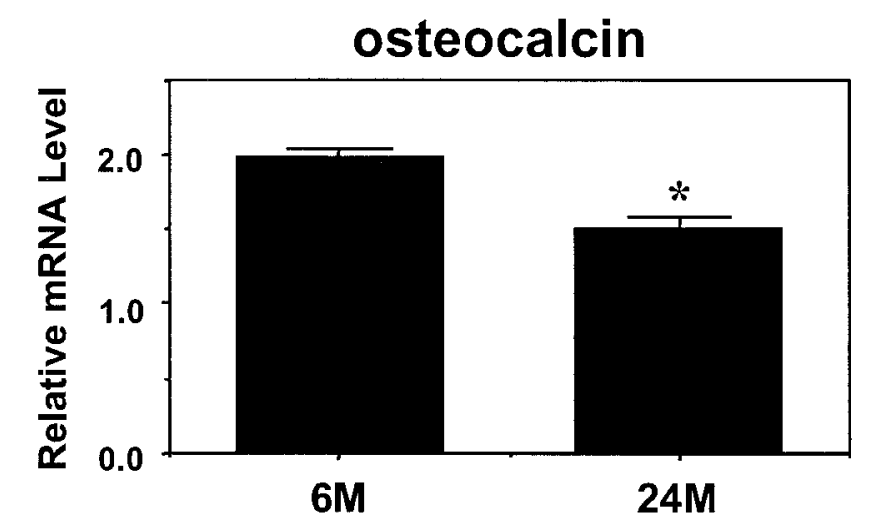

alkaline phosphatase

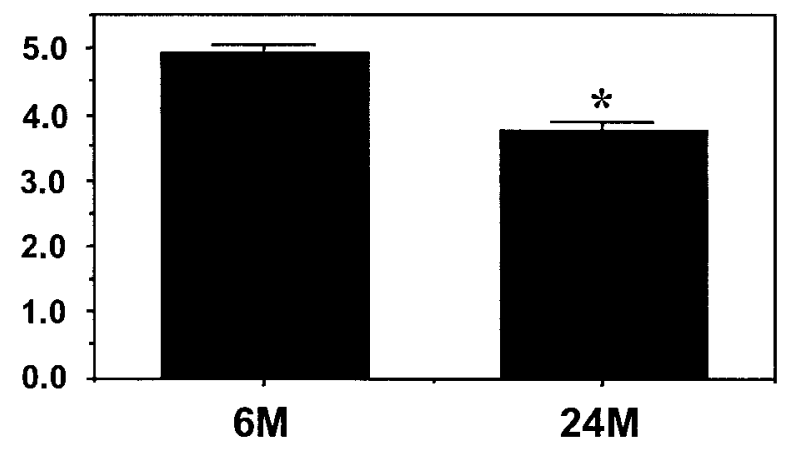

collagen $\alpha_{1}$ (I)
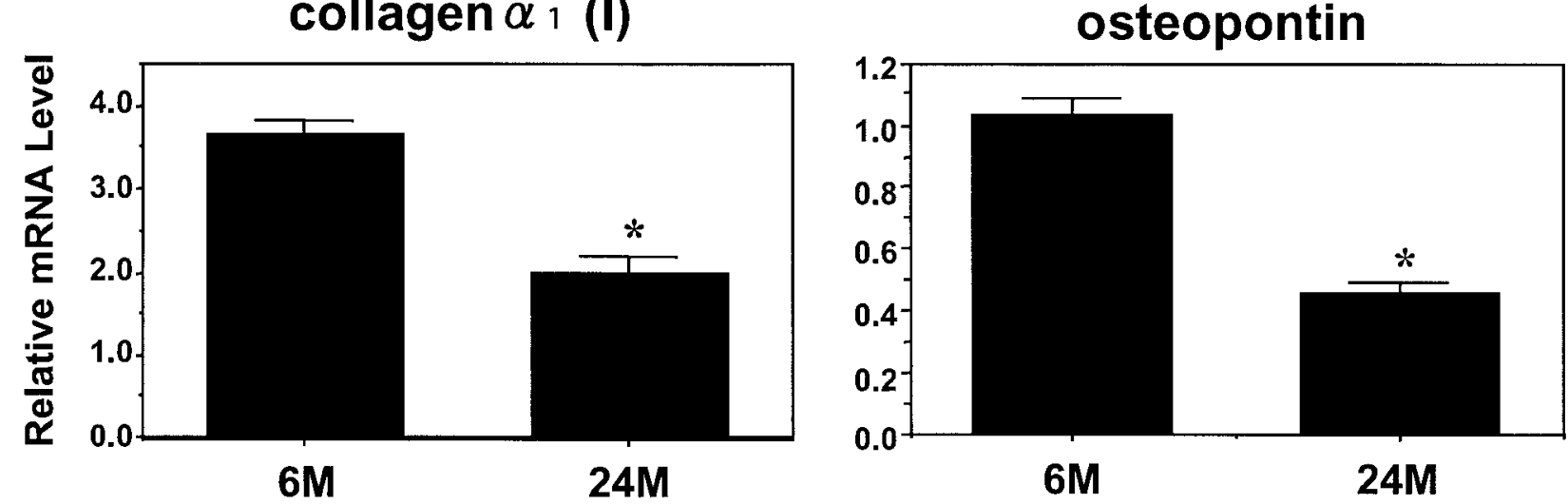

Figure 1 Effect of age on the mRNA levels of osteoblast markers after bone marrow ablation. Bone marrow was aspirated from the femurs of adult (6-month-old; 6M) or old (24-month-old; 24M) rats. At day 6, total RNA was prepared from the femurs. The level of each specific mRNA was quantitated by dot blot analysis and normalized with poly $(A)^{+}$RNA. Values shown are means \pm S.E. for six to seven rats. ${ }^{*} P<0 \cdot 0001$ (unpaired $t$-test)

achieved with either IGF-I or PDGF alone. At $50 \mathrm{ng} /$ day of the PDGF/IGF-I treatment, no dose-response effects were observed. The effect of the two agents on gene expression was analyzed by Northern blot hybridization, and Fig. 4 shows a representative result.

\section{Discussion}

Impairment of bone formation activity in senescence is in part due to the low level of growth factors. Although no data on the levels of PDGF are available, there is some evidence that serum levels and the expression of IGF-I decline in senescence (Rudman et al. 1981, Florini et al. 1985, Tanaka et al. 1996). In addition, it has been demonstrated that the age-dependent decline in the growth hormone/IGF-I/IGF-binding protein axis is associated with the age-related loss of bone mass (Sugimoto et al. 1997). A recent study has shown that the age-related decline in IGF-I can be attributed in part to impaired calcium absorption with age (Fatayerji et al.
2000). Decreased calcium absorption would eventually cause a decrease in serum calcium, resulting in a compensatory increase in parathyroid hormone in aging.

The aim of the present study was to explore the possibility that growth factor can be used to up-regulate the impaired bone formation activity in old rats. We tested the effect of growth factors on the gene expression of bone matrix proteins in femurs during the process of bone formation after marrow ablation. We have previously shown that gene expression correlated with histomorphometric evidence of bone formation in a bone marrow ablation model (Liang et al. 1992). Several reports have also described the correlation between the mRNA levels of characteristic osteoblast products and bone formation as assessed by bone histomorphometry (Turner \& Spelsberg 1991, Wakley et al. 1992, Rantakokko et al. 1999). After the removal of the marrow, the medullary cavity is filled with a blood clot, and the osteoprogenitor cells in the region adjacent to the endosteal surface proliferate and differentiate into preosteoblasts. These cells deposit trabecular bone in the cavity, with their maximal activity 


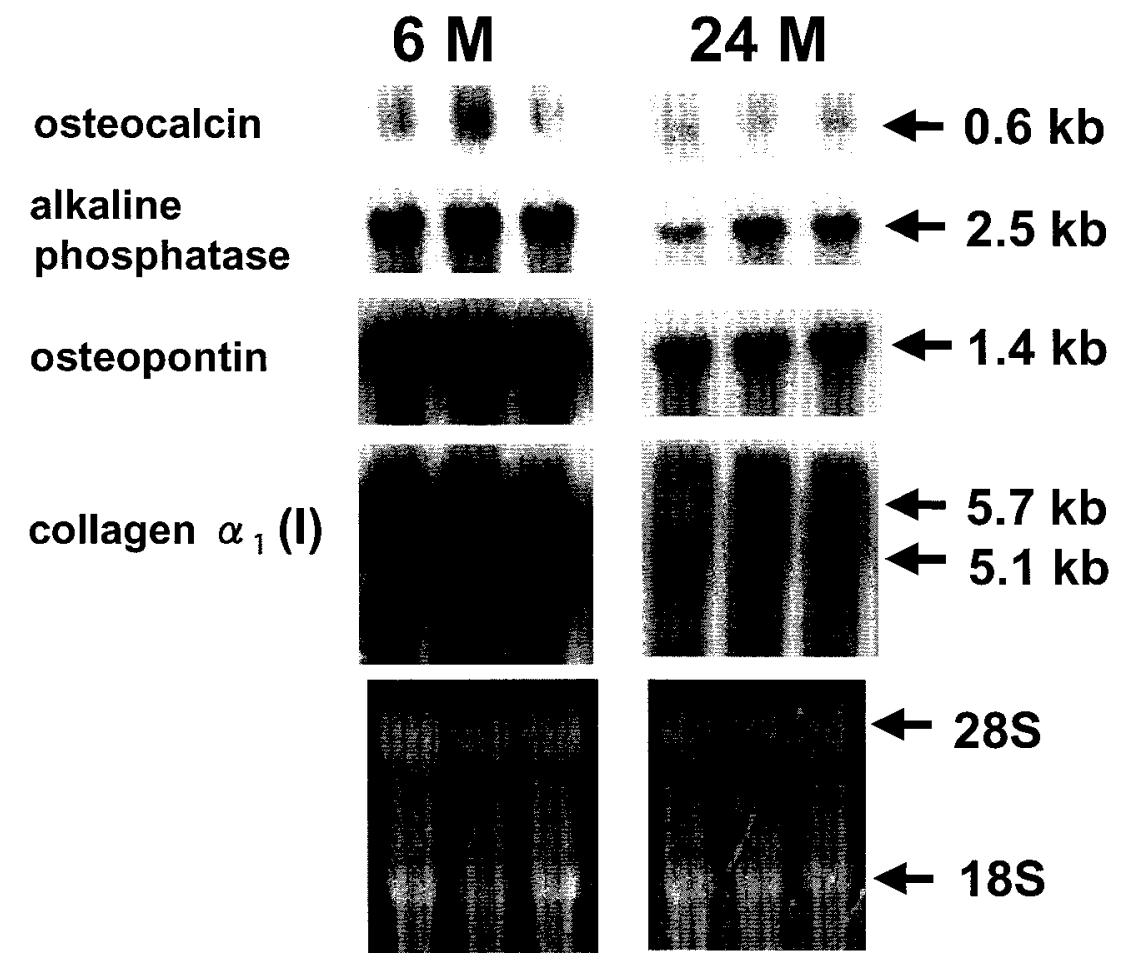

Figure 2 Representative Northern blots of femoral mRNA after bone marrow ablation. Bone marrow was aspirated from the femurs of adult $(6 \mathrm{M})$ or old $(24 \mathrm{M})$ rats. Total RNA was prepared from the femurs, and the level of each specific mRNA was analyzed by Northern blot hybridization. The results from three representative samples are shown. Ethidium bromide staining of ribosomal RNA (28S and 18S) in the same gel is also shown.

occurring on day 6 (Patt \& Maloney 1975, Liang et al. 1992). Using this model, we have shown that these events are attenuated in old rats (Liang et al. 1992). The present study confirmed the observation that the mRNA levels of osteoblast markers were consistently lower in bones from old rats. We then tested the effect of PDGF, IGF-I and a combination of the two on the expression of osteoblast markers in order to explore the possibility that growth factors can stimulate the expression of osteoblast-related genes and, thus, can restore bone formation activity in old rats.

Our results demonstrated that the administration of PDGF directly into the femur after marrow ablation failed to enhance the mRNA levels of osteoblast markers, with the exception of OP. Our previous studies in bone marrow stromal cells have shown that PDGF stimulated OP mRNA expression in a dose-dependent manner (Tanaka \& Liang 1995). Thus, the results from our in vivo experiments are consistent with our previous results that PDGF stimulates $\mathrm{OP}$ expression. In addition, PDGF also has a modest inhibitory effect on the differentiated function of osteoblasts, as previously suggested in an in vitro study (Canalis et al. 1989, Hock \& Canalis 1994, Tanaka Liang 1995). That finding supports the negative results for COLI, OC and AP expression that were observed in the present experiment. As we have shown previously, IGF-I was partially effective in stimulating gene expression in old rats (Tanaka et al. 1994). The infusion of IGF-I enhanced the mRNA expression of COLI, AP and OP but not OC. Thus, our data clearly show that IGF-I is more effective than PDGF in stimulating the expression of osteoblastrelated genes in old bone.

The combination of PDGF and IGF-I appeared to have minimal additional effects on the specific expression of bone products as compared with IGF-I. In contrast to the IGF-I treatment, however, the expression of OC was also stimulated by the PDGF plus IGF-I combination in old bone, in addition to the expression of COLI, AP and OP. Neither IGF-I nor PDGF alone was able to stimulate OC expression. Since OC is known to be produced by mature osteoblasts and to regulate the calcification of bone tissue, it is possible that the PDGF plus IGF-I treatment may stimulate maturation and mineralization in the process of bone formation. Our assumption is supported by a previous report that found that the PDGF plus IGF-I combination enhanced the density of mineralization in the callus, which was not affected by either PDGF or IGF-I alone (Lynch et al. 1994). In addition, it should be noted here that, since high doses of growth factors have undesirable side-effects, it would be beneficial if the 

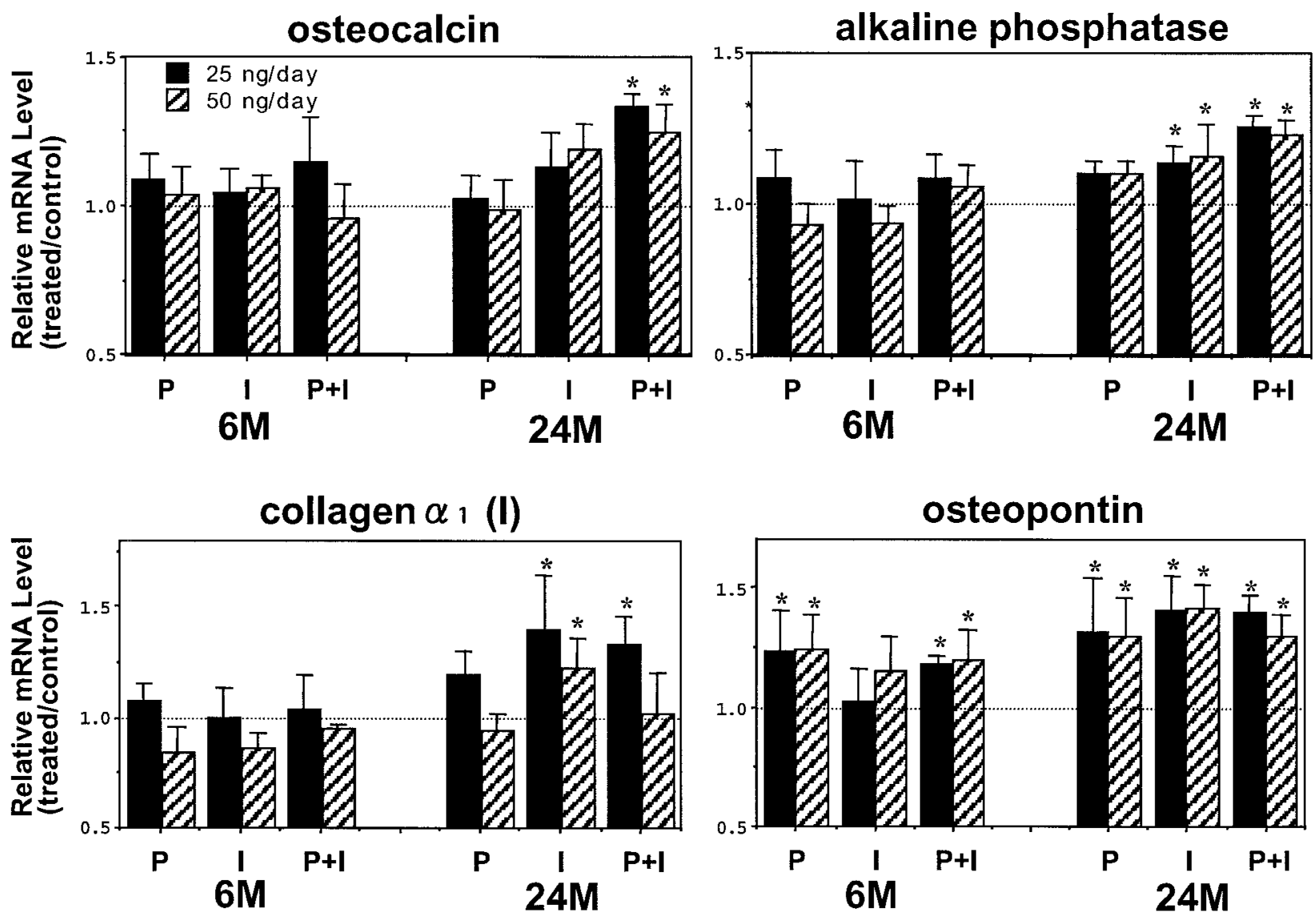

Figure 3 Effect of IGF-I and PDGF administered in vivo on the expression of osteoblast markers. Bone marrow was aspirated from the femurs of adult $(6 \mathrm{M})$ or old $(24 \mathrm{M})$ rats. One leg served as the control and the contralateral leg was infused with 25 or $50 \mathrm{ng} / \mathrm{day}$ of the growth factors for 5 days. The level of each specific mRNA was quantitated by dot blot analysis and normalized with poly(A) ${ }^{+} \mathrm{RNA}$. Results are expressed as the ratio of the treated leg mRNA to the control leg mRNA. P=PDGF; I=IGF-I. Values shown are the means \pm S.E. for six to seven animals. ${ }^{*} P<0 \cdot 05$ vs control (paired $t$-test).

combination of growth factors could result in a reduced dose of each growth factor.

In our present study, the treatment of growth factors was not effective in stimulating the mRNA expression of osteoblast-related genes other than osteopontin in adult rats. These age-dependent effects may be explained by the fact that the level of the growth factors may be altered in old rats, as mentioned earlier in this discussion. Moreover, using the marrow ablation model, we also observed that IGF-I gene expression in the process of bone formation decreased in old rats (Tanaka et al. 1996). In this regard, it is possible that the expression of osteoblast-related genes may be fully activated, probably due to the relatively high level of the serum proteins of growth factors after bone marrow ablation in adult rats, and that an additional infusion of growth factors may not be able to induce further enhancement. Indeed, the mRNA levels of osteoblast markers were consistently higher in bones from adult rats, as shown in the present study. A previous study demonstrated a similar age-related difference in the responses to growth factors (Spencer et al. 1991). In that study, IGF-I infusion stimulated both cortical bone formation and trabecular bone apposition in 12-month-old rats, but not in 6- to 7-week-old rats.

Treatment with the PDGF plus IGF-I combination in old rats was partially effective in restoring the age-related decrease in the gene expression of osteoblast markers, but the actual mRNA level of treated limbs in old rats was still lower than that in untreated adult rats. Given the complexity of bone formation and the many growth factors involved in the regulation, it is reasonable that other growth factors may also be involved in reduced bone formation activity in senescence. Furthermore, the effect of growth factors may be influenced by the timing or duration of their administration in the experiment. Although we analyzed gene expression at day 6 because the maximal activation of gene expression was observed in our previous experiment at this time, it is possible that a shorter or longer period of treatment or sequential treatment may produce a more pronounced cellular response. 


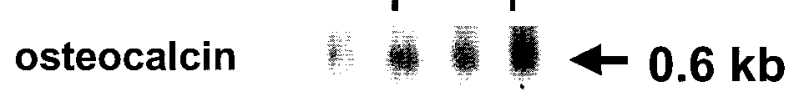

\section{alkaline phosphatase}

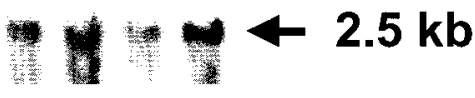

\section{osteopontin}

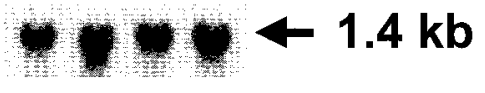

\section{collagen $\alpha_{1}(\mathrm{I})$}
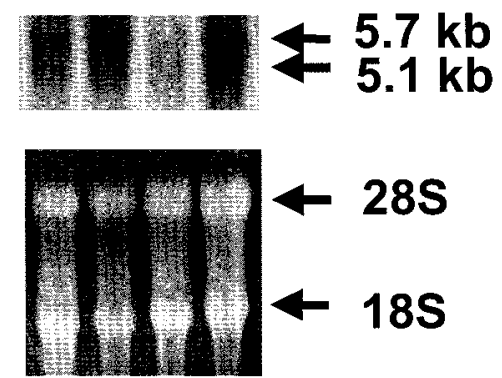

Figure 4 Northern blot analysis of femoral mRNA after treatment with PDGF plus IGF-I in old rats. The bone marrow was aspirated from femurs. One leg served as the control and the contralateral leg was infused with $25 \mathrm{ng} /$ day PDG plus IGF-I for 5 days. Total RNA was prepared from the femurs and the level of each specific mRNA was analyzed by Northern blot hybridization. The results from two representative samples are shown. Ethidium bromide staining of ribosomal RNA (28S and 18S) in the same gel is shown at the bottom. ( - ) control; (+) PDGF plus IGF-I.

Thus, the stimulation of gene expression by treatment with the PDGF plus IGF-I combination in the present study should be viewed as a limited result rather than as indicative of the results that might be achieved with more refined interventions.

In conclusion, the results from our in vivo model clearly show that IGF-I is a better stimulator of osteoblast marker expression than is PDGF in old bone. Treatment with the PDGF plus IGF-I combination partially restored the deficit in gene expression activity in old bone, but the effect was only slightly better than that of IGF-I alone. Additional investigations in combination with other growth factors will be needed to establish the efficacy and utility of growth factor treatment for age-related bone loss.

\section{References}

Canalis E 1980 Effect of insulinlike growth factor I on DNA and protein synthesis in cultured rat calvaria. Journal of Clinical Investigation 66 709-719.

Canalis E, McCarthy TL \& Centrella M 1989 Effects of plateletderived growth factor on bone formation in vitro. Journal of Cellular Physiology 140 530-537.

Centrella M, McCarthy TL \& Canalis E 1989 Platelet-derived growth factor enhances deoxyribonucleic acid and collagen synthesis in osteoblast-enriched cultures from fetal rat parietal bone.

Endocrinology 125 13-19.
Christiansen C 1992 Prevention and treatment of osteoporosis: a review of current modalities. Bone 13 S35-S39.

Fatayerji D, Mawer EB \& Eastell R 2000 The role of insulin-like growth factor I in age-related changes in calcium homeostasis in men. Journal of Clinical Endocrinology and Metabolism 85 4657-4662.

Florini JR, Prinz PN, Vitiello MV \& Hintz RL 1985 Somatomedin-C levels in healthy young and old men: relationship to peak and 24-hour integrated levels of growth hormone. Journal of Gerontology 40 2-7.

Genovese C, Rowe D \& Kream B 1984 Construction of DNA sequences complementary to rat alpha 1 and alpha 2 collagen mRNA and their use in studying the regulation of type I collagen synthesis by 1,25-dihydroxyvitamin D. Biochemistry 23 6210-6216.

Hock JM \& Canalis E 1994 Platelet-derived growth factor enhances bone cell replication, but not differentiated function of osteoblasts. Endocrinology 134 1423-1428.

Hock JM, Centrella M \& Canalis E 1988 Insulin-like growth factor I has independent effects on bone matrix formation and cell replication. Endocrinology 122 254-260.

Hollander MC \& Fornace AJ Jr 1990 Estimation of relative mRNA content by filter hybridization to a polythymidylate probe. Biotechniques 9 174-179.

Howes R, Bowness JM, Grotendorst GR, Martin GR \& Reddi AH 1988 Platelet-derived growth factor enhances demineralized bone matrix-induced cartilage and bone formation. Calcified Tissue International 42 34-38.

Isgaard J, Nilsson A, Lindahl A, Jansson JO \& Isaksson OG 1986 Effects of local administration of GH and IGF-1 on longitudinal bone growth in rats. American Journal of Physiology 250 E367-E372.

Liang CT, Barnes J, Seedor JG, Quartuccio HA, Bolander M, Jeffrey JJ \& Rodan GA 1992 Impaired bone activity in aged rats: alterations at the cellular and molecular levels. Bone 13 435-441.

Lynch SE, Nixon JC, Colvin RB \& Antoniades HN 1987 Role of platelet-derived growth factor in wound healing: synergistic effects with other growth factors. PNAS $\mathbf{8 4}$ 7696-7700.

Lynch SE, Buser D, Hernandez RA, Weber HP, Stich H, Fox CH \& Williams RC 1991 Effects of the platelet-derived growth factor/ insulin-like growth factor-I combination on bone regeneration around titanium dental implants. Results of a pilot study in beagle dogs. Journal of Periodontology 62 710-716.

Lynch SE, Trippel SB \& Finkelman RD 1994 The combination of platelet-derived growth factor-BB and insulin-like growth factor-I stimulates bone repair in adult Yucatan miniature pigs. Wound Repair and Regeneration 2 182-190.

Nemeth GG, Heydemann A \& Bolander ME 1989 Isolation and analysis of ribonucleic acids from skeletal tissues. Analytical Biochemistry 183 301-304.

Noda M, Yoon K, Thiede M, Buenaga R, Weiss M, Henthorn P, Harris H \& Rodan GA 1987 cDNA cloning of alkaline phosphatase from rat osteosarcoma (ROS 17/2.8) cells. Journal of Bone and Mineral Research 2 161-164.

Patt HM \& Maloney MA 1975 Bone marrow regeneration after local injury: a review. Experimental Hematology 3 135-148.

Pfeilschifter J, Oechsner M, Naumann A, Gronwald RG, Minne HW \& Ziegler R 1990 Stimulation of bone matrix apposition in vitro by local growth factors: a comparison between insulin-like growth factor I, platelet-derived growth factor, and transforming growth factor beta. Endocrinology 127 69-75.

Rantakokko J, Uusitalo H, Jamsa T, Tuukkanen J, Aro HT \& Vuorio E 1999 Expression profiles of mRNAs for osteoblast and osteoclast proteins as indicators of bone loss in mouse immobilization osteopenia mode. Journal of Bone and Mineral Research $\mathbf{1 4}$ 1934-1942.

Rudman D, Kutner MH, Rogers CM, Lubin MF, Fleming GA \& Bain RP 1981 Impaired growth hormone secretion in the adult population: relation to age and adiposity. Journal of Clinical Investigation 67 1361-1369. 
Samuels A, Perry MJ \& Tobias JH 1999 High-dose estrogen induces de novo medullary bone formation in female mice. Journal of Bone and Mineral Research 14 178-186.

Samuels A, Perry MJ, Goodship AE, Fraser WD \& Tobias JH 2000 Is high-dose estrogen-induced osteogenesis in the mouse mediated by an estrogen receptor? Bone 27 41-46.

Schlechter NL, Russell SM, Spencer EM \& Nicoll CS 1986 Evidence suggesting that the direct growth-promoting effect of growth hormone on cartilage in vivo is mediated by local production of somatomedin. PNAS 83 7932-7934.

Spencer EM, Liu CC, Si EC \& Howard GA 1991 In vivo actions of insulin-like growth factor-I (IGF-I) on bone formation and resorption in rats. Bone 12 21-26.

Sugimoto T, Nishiyama K, Kuribayashi F \& Chihara K 1997 Serum levels of insulin-like growth factor (IGF) I, IGF-binding protein (IGFBP)-2, and IGFBP-3 in osteoporotic patients with and without spinal fractures. Journal of Bone and Mineral Research 12 1272-1279.

Tanaka H \& Liang CT 1995 Effect of platelet-derived growth factor on DNA synthesis and gene expression in bone marrow stromal cells derived from adult and old rats. Journal of Cellular Physiology 164 367-375.

Tanaka H, Quarto R, Williams S, Barnes J \& Liang CT 1994 In vivo and in vitro effects of insulin-like growth factor-I (IGF-I) on femoral mRNA expression in old rats. Bone 15 647-653.
Tanaka H, Barnes J \& Liang CT 1996 Effect of age on the expression of insulin-like growth factor-I, interleukin-6, and transforming growth factor-beta mRNAs in rat femurs following marrow ablation. (Published erratum appears in Bone 199619 206.) Bone 18 473-478.

Turner RT \& Spelsberg TC 1991 Correlation between mRNA levels for bone cell proteins and bone formation in long bones of maturing rats. American Journal of Physiology 261 E348-E353.

Wakley GK, Portwood JS \& Turner RT 1992 Disuse osteopenia is accompanied by downregulation of gene expression for bone proteins in growing rats. American Journal of Physiology 263 E1029-E1034.

Weinreb M, Shinar D \& Rodan GA 1990 Different pattern of alkaline phosphatase, osteopontin, and osteocalcin expression in developing rat bone visualized by in situ hybridization. Journal of Bone and Mineral Research 5 831-842.

Yoon K, Buenaga R \& Rodan GA 1987 Tissue specificity and developmental expression of rat osteopontin. Biochemical and Biophysical Research Communications 148 1129-1136.

Received 11 February 2002

Accepted 8 March 2002 